\title{
\$5 АДМИНИСТРАТИВНОЕ
}

Трунцевский Ю.В.

\section{ПОНЯТИЕ, СОДЕРЖАНИЕ И ВИДЫ МЕР УГОЛОВНО-ПРАВОВОГО И АДМИНИСТРАТИВНОГО ВОЗДЕЙСТВИЯ}

Аннотачия Предметом статьи являюотся проблеми правового и организачионного характера связанныес уголовным и административным воздействием на нарушителей правовых норм. Автором подробно проводится теоретико-правовой анализ концепций правового воздействия с позиции уголовного и административного права. Рассматриваются авторские позиции относительно понятия правового воздействия. Основное внимание в статье уделяется разработки методов и методологии правового воздействия как средства обеспечения правопорядка. Кроме того, в статье проводится теоретико-правовой анализ понятий концепций относительно взаимосвязи уголовно-правового и административного воздействия (принуждения). Методологическую основу статьи составили современные достижения теории познания. В процессе исследования применялись общефилософский, теоретический, общефилософские методы (диалектика, системный метод, анализ, синтез, аналогия, дедукция, наблюдение, моделирование), традиционно правовые методы (формально-логический), а также методы, используемые в конкретно-социологических исследованиях (статистические, экспертные оценки и др.). В статье отмечается, что исходя из того, что Уголовный кодекс РФ и КоАП России не содержит понятия и перечня видов мер уголовно-правового и административного воздействия. В статье сформулировано понятие мер уголовноправового воздействия, как форм и средств специальной деятельности государства воздействия и определены виды таких мер в зависимости от целей воздействия (уголовно-правовые меры предупреждения и пресечения преступлений, меры реализации уголовной ответственности), характера воздействия (меры уголовно-предупредительного, уголовно-профилактического, уголовно-восстановительного и уголовно-исправительного воздействия (карательные (наказание) и испытательные меры), меры обеспечения реализации уголовной ответственности, меры единичной не реабилитирующей декриминализации и меры уголовно-лечебного воздействия.

Ключевые слова: предупреждение, проступок, преступление, уголовный, административный, закон, ответственность, наказание, полиция, принуждение.

Review: The article focuses on legal and organizational problems of criminal and administrative influence on the infringers of legal rules. The author carries out theoretical and legal analysis of the concepts of legal influence from the position of criminal and administrative law. The article describes the author's positions regarding the notion of legal influence. The main attention is paid to the development of methods and methodology of legal influence as the means of law and order provision. In addition, the article presents a theoretical and legal analysis of concepts regarding the interrelation between criminal and administrative influence (coercion). The methodology of the research is based on the resent achievements of epistemology. The author uses the general philosophical and theoretical methods (dialectics, the systems method, analysis, synthesis, analogy, deduction, observation, modeling), the traditional legal methods (formal logical), as well as the methods used in the concrete sociological research (the statistical method, expert evaluations, etc.).The article notes that the Criminal code and the Code of Administrative Offences of the Russian Federation do not contain the concept and the list of types of measures of criminal-legal and administrative influence. The article defines the measures of criminal-legal influence as the forms and special activities of the state and defines the types of such measures depending on the purpose of influence (criminal law measures to the prevention and suppression of crime, measures of the criminal liability), the nature of impact (the preventive measures and the measures of criminal liability imposition), the character of influence (the preventive, restorative and correctional measures, the measures of criminal liability implementation, the measures of single non-rehabilitating decriminalization, and the medical measures).

Keywords: responsibility, law, administrative, criminal, crime, misconduct, warning, punishment, police, coercion.

Статья подготовлена по результатам исследований, выполненных за счет бюджетных средств по Государственному заданию Финуниверситета 2015 года 
$\mathrm{H}$ есмотря на то, что Уголовный кодекс РФ не содержит понятия мер уголовно-правового воздействия и в нем не закреплен перечень их видов, нельзя не согласиться, что в основе всех организационных либо правовых мер, направленных на преступность, лежит уголовный закон и «борьба с преступностью заключается главным образом в применении мер уголовно-правового воздействия» [8, с. 3]. Именно уголовный закон устанавливает виды наказаний и иные меры уголовно-правового характера за совершение преступлений (ст. 2 УК РФ).

Учитывая, что «воздействовать» - значит действовать в отношении чего-то, кого-то, «влиять»на «это», уголовно-правовое воздействие можно представить как специальную деятельность государства, общества и отдельных граждан, в сфере противодействия преступности, осуществляемую посредством использования, при наличии определенных условий (потребность профилактики, пресечение преступлений, наказание за его совершение и др.), возможностей и средств, закрепленных в уголовном законе, составляющих в своей совокупности механизм уголовно-правовой воздействия на преступность.

Анализ текста уголовного закона позволяет сделать вывод о многообразии уголовно-правовых средств воздействия на преступность, что, в первую очередь связано с задачами уголовно-правовой политики - это профилактика преступности, защита и поддержка потерпевших от преступлений, исполнение уголовных наказаний и иных мер уголовно-правового характера, социальная реабилитация и надзор за лицами, отбывшими уголовное наказание [11].

Такой вывод вытекает из анализа действующего законодательства, регулирующего отношения по поводу противодействия наиболее опасным преступным проявлениям - терроризма [21], экстремизма [22] и коррупции [23], и показывающего, что закрепленные в данных законах специальные меры, осуществляются в деятельности органов государственной власти и органов местного самоуправления, а также физических и юридических лиц, и объединены общим понятием - «противодействие»: предупреждение преступлений (профилактика); выявление, пресечение, раскрытие и расследование преступлений (борьба с преступлениями); минимизация и (или) ликвидация последствий преступлений. То есть меры противодействия совпадают с задачами уголовной политики, опирающейся на уголовный закон. Поэтому можно предположить, что и главной целью применения мер уголовно-правового воздействия является противодействие преступности.

Итак, несмотря на то, что указанные виды воздействия на преступность в этих законах относятся исключительно к отдельным видам преступлений, нет никаких сомнений, что законодатель в подобной классификации мер выразил свое утвердившееся отношение по поводу содержания направлений противодействия преступности $[17$, с. 169], включающее:

1) предупреждение преступлений (профилактика). Применительно, например, к полиции как базовому элементу «системы обеспечения общественного порядка и противодействия преступности» [5] - это деятельность служб, подразделений и сотрудников органов внутренних дел, общества и отдельных граждан, осуществляемая в пределах их компетенции, направленная на недопущение преступлений путем выявления, устранения или нейтрализации причин, условий и обстоятельств, способствующих их совершению, оказания профилактического воздействия на лиц с противоправным поведением [1].

2) Борьба с преступлениями, как одно из основных направлений противодействия преступности включает в себя карательные, силовые меры воздействия (выявление, пресечение, раскрытие и расследование преступлений), правомочие на применение которых имеют:

- правоохранительные органы - это, например, «действенные меры по пресечению фактов контрабанды оружия, боеприпасов, взрывчатых веществ, бронетехники, наркотиков через Государственную границу Российской Федерации» [2]). В соответствии со статьей 10. «Борьба с преступностью» Федерального закона от 3 апреля 1995 № 40-Ф3 (ред. от 22.12.2014) «0 Федеральной службе безопасности» [24] деятельность органов федеральной службы безопасности в сфере борьбы с преступностью осуществляется в соответствии с законодательством об оперативно-розыскной деятельности, уголовным и уголовно-процессуальным законодательством Российской Федерации, а также данным Федеральным законом;

- $\quad$ юридические и должностные лица правоохранительной направленности. Так, органы внутренних дел обеспечивают взаимодействие с частными охранными организациями и частными детективами, вырабатывают эффектив- 
ные формы и методы их привлечения к борьбе с преступностью [3];

- $\quad$ граждане в рамках реализации права на необходимую оборону, либо задержания лица, совершившего преступление (ст. 37, 38 УК РФ);

3) минимизация и (или) ликвидация последствий преступлений, как совокупность мер организационного, технического, правового, социального, экономического, медицинского и иного характера, а также сокращение масштабов и уменьшения тяжести вреда, причиняемого преступлениями.

Наличие общих целей уголовно-правового противодействия преступности не исключает необходимости формулирования самостоятельных целей для каждой группы средств воздействия, отличающихся присущим только им предполагаемым результатом реализации [8, с. 13].

Подобную позицию занимает, например, В.Ф. Ширяев, определяя систему мер уголовно-правового воздействия как совокупность ограниченного количества элементов, носящих основной или вспомогательный характер, объединенных результатом ее направленности, выраженным в целях наказаний, регламентированных УК РФ [26, с. 49]. Похожую точку зрения высказывают и другие ученые, под уголовно-правовым воздействием понимающие способы уголовно-правового выражения государственного принуждения, применяемые к лицу, совершившему общественно опасное деяние, запрещенное уголовным законом, путем наложения на осужденного дополнительных правоограничений (лишения либо ограничения прав и свобод лица) [19; 9, с. 20].

Вместе с тем, круг отношений, на которые воздействуют уголовно-правовые меры значительно шире вышеуказанных, носящих исключительно правоограничивающий характер. Считаем целесообразным меры, не содержащие уголовно-правовых ограничений, но включенные в УК РФ, по своей правовой природе также отнести к мерам уголовно-правового воздействия. Общими признаками всех мер уголовно-правового воздействия при этом являются:

- их закрепление в УК РФ;

- наличие правомочий их применения, используемых правоохранительными органами, их должностными лицами, судом, гражданами;

- $\quad$ как правило, процессуальный порядок их применения.

Гришанин П.Ф. такие меры предлагает группировать следующим образом:
- уголовно-правовые меры предупреждения преступлений;

- уголовно-правовые меры пресечения преступлений;

- уголовно-правовые меры реализации уголовной ответственности [8, с. 3].

С данной классификацией следует согласиться. Вместе с тем, анализ видов подобных мер в действующем уголовном законе, позволяет уточнить и изменить перечень видов мер уголовно-правового воздействия, где относительная самостоятельность этих мер по целям и содержанию является основой для их дифференциации.

К первой группе следует отнести уголовноправовые меры предупреждения (профилактики) преступлений:

- добровольный отказ (ст. 31 «... прекращение лицом приготовления к преступлению либо прекращение действий (бездействия), непосредственно направленных на совершение преступления, если лицо осознавало возможность доведения преступления до конца», 205.4 - добровольное прекращение участия в террористическом сообществе и сообщение о его существовании, а также ст.ст. 205.5, 206, 208, 210, 282.1, 228.2) - как мера уголовно-правового воздействия, побуждающая правонарушителя к добровольному и окончательному отказу от продолжения начатых противоправных действий;

- $\quad$ уголовная ответственность за преступления с двойной превенцией. «Уголовно-правовые нормы с двойной превенцией - это нормы, устанавливающие уголовную ответственность за общественно опасные деяния, которые обусловливают последующее совершение других преступлений» [16, с. 170-171]. Под данную категорию подпадают преступления, предусмотренные ст.ст. 222-223, 326, 327, 327.1 УК РФ, а также ст. 115, 116, 117, 119, 135, 139 , 150, 151, 151.1, 156, 215, 217.1, 218, 219, 230 УК РФ и др., то есть те общественно опасные деяния, которые сами, как правило, не представляют большой общественной опасности, но могут привести к совершению более значимых по степени и характеру опасности, по тяжести наступивших последствий преступления. В данных мерах уголовно-правового воздействия содержится предупредительный потенциал уголовного законодательства;

- принудительные меры медицинского характера (глава 15), целями применения которых яв- 
ляются не только излечение определенной категории лиц или улучшение их психического состояния, но и предупреждение совершения ими новых деяний, предусмотренных статьями Особенной части УК РФ (ст. 98);

- профилактика преступлений, ресоциализация лиц, отбывших наказание, путем возложения на лицо обязанностей, способствующих его исправлению: пройти курс лечения от алкоголизма, наркомании, токсикомании или венерического заболевания, трудиться (трудоустроиться) либо продолжить обучение в общеобразовательной организации и др. (ч. 5 ст. 73); при освобождении от наказания судом помещение несовершеннолетних в специальное учебно-воспитательное учреждение закрытого типа (ч. 2 ст. 87); требование возвратиться в образовательную организацию либо трудоустроиться с помощью специализированного государственного органа (ч. 4 ст. 91); и др. Так, назначение принудительных мер медицинского характера в виде принудительного наблюдения и лечения у врача-психиатра в амбулаторных условиях к лицам, осужденным за преступления, совершенные в состоянии вменяемости, но нуждающимся в лечении психических расстройств, не исключающих вменяемости (ч. 2 ст. 99), можно отнести к мерам социальной реабилитации. В ст. 72.1 закреплена обязанность лица, признанного больным наркоманией, пройти лечение от наркомании и медицинскую и (или) социальную реабилитацию);

- минимизация последствий - деятельное раскаяние и возмещение вреда (ст. 75 - лицо «... добровольно явилось с повинной, способствовало раскрытию и расследованию преступления, возместило причиненный ущерб или иным образом загладило вред, причиненный в результате преступления, и вследствие деятельного раскаяния перестало быть общественно опасным», 76, 76.1, глава 15.1 «Конфискация имущества», 126, 127.1, 134, 178 - лицо «... возместило причиненный этим преступлением ущерб или иным образом загладило причиненный вред...», 184, 199 - полная уплата суммы недоимки и соответствующих пеней, а также суммы штрафа в размере, определяемом в соответствии с Налоговым кодексом Российской Федерации, 200.1 - добровольная сдача наличных денежных средств и (или) денежных инструментов, 204, 206, 212, 228, 228.3, 275, 291, 291.1, 307).
Предложение относить к данным мерам предупреждения пропаганду законодательства [8, с. 12] представляется не совсем верным, учитывая, что характер (формы) воздействия при пропаганде (устно, в печати и наглядно, лекция, беседа и т.п.) носит не уголовно-правовой, а право-культурный, воспитательный характер (воздействие на сознание и настроение людей с целью побудить в них активность), то есть меры по пропаганде уголовного закона не регламентированы УК РФ.

Правовой пропагандой занимается множество субъектов, и применительно к пропаганде правопослушного поведения можно выделить воспитательную роль судебных процессов. Это меры достижения максимального воспитательного воздействия судебного процесса, например, в отношении несовершеннолетних (статьи 73, 421 УПК РФ) [4], то есть меры уголовно-процессуального воздействия.

Также нельзя согласиться с мнением о том, что официальное предостережение потенциальных правонарушителей, является уголовно-правовой мерой [8, с. 13]. В соответствии с п. 3 ст. 63 «Применение принудительных мер воспитательного характера к несовершеннолетним» УК РСФСР предостережение было отнесено к принудительным мерам воспитательного характера [20]. В настоящее время такое предостережение регулируются административным, уголовно-исполнительным либо уголовно-процессуальным законодательством, и право на применение данного взыскания имеет ограниченный, законодательно установленный круг лиц. Так, например, за нарушение осужденным в течение одного года после вынесения предупреждения любого из нарушений, указанных в ч. 1 ст. 58 УИК РФ, уголовно-исполнительная инспекция применяет к нему меру взыскания в виде официального предостережения о недопустимости нарушения установленных судом ограничений.

Вместе с тем, такая мера освобождения от уголовной ответственности, применяемая к несовершеннолетним, совершившим преступление небольшой или средней тяжести, как предупреждение, по своей цели и форме имеет две цели - профилактическая и пропаганда-воспитательная: «предупреждение состоит в разъяснении несовершеннолетнему вреда, причиненного его деянием, и последствий повторного совершения преступлений, предусмотренных настоящим Кодексом» (ст. 91 УК РФ).

То есть, по форме предупреждение - это не просто официальная передача каких-либо сведений, а разъяснение в индивидуальном сознании 
(индивидуальная пропаганда) правил законопослушного поведения, а также недопустимости повторного совершения преступлений, порицание действий лица при совершении правонарушения, с целью формирования у него правового мировоззрения и поддержания у него в последующем правомерного поведения, что и является мерой индивидуальной профилактики.

Во вторую группу - уголовно-правовые меры пресечения преступлений - входят:

- пресечение преступлений путем причинения вреда посягающему лицу в состоянии необходимой обороны (ст. 37); причинение вреда лицу, совершившему преступление, при его задержании (ст. 38);

- пресечение преступлений на стадияхумышленного неоконченного преступления (уголовная ответственность за приготовление (ч. 2 ст. 30) и уголовная ответственность за покушение на преступление (ч. 3 ст. 30);

- добровольное сообщение (например, добровольное сообщение о подкупе органу, имеющему право возбудить уголовное дело (ст. 204);

- своевременное предупреждение органов власти или иным способом способствование предотвращению осуществления террористического акта (ст. 205, 205.1, 205.3). Исходя из текста примечаний к статьям, предусматривающим уголовную ответственность за совершение преступлений террористической направленности, других статей УК РФ (ст. 275, 282.3), предотвращение совершения преступления исполнителем, нельзя отнести к отдельной мере уголовно-правового воздействия, так как такое недопущение совершения преступления само по себе, как самостоятельная мера, исходя из текста УК РФ, не применяется, и всегда является следствием (последствием, целью) применения другой меры - своевременное предупреждение органов власти или иные способы способствования предотвращению преступления; прекращение участия в преступном сообществе (преступной организации); ст. 210 - активное способствование пресечению этих преступлений; добровольная сдача наркотических средств и т.п. (ст. 228, 228.3); ст. 275 - добровольное и своевременное сообщение органам власти или иным образом способствование предотвращению дальнейшего ущерба интересам Российской Федерации; ст. 282.2 - добровольное прекращение участия в деятельности общественного или религиоз- ного объединения либо иной организации; ст. 291 - добровольное сообщение о даче взятки органу, имеющему право возбудить уголовное дело; ст. 291.1).

Третью группу мер уголовно-правового воздействия составляют меры реализации уголовной ответственности.

Кформам реализацииуголовной ответственности принято относить: 1) наказание и 2) осуждение без назначения наказания или без его отбывания.

Уголовную ответственность в этой связи предлагается рассматривать как основанную на нормах уголовного права обязанность лица, совершившего преступление, претерпевать неблагоприятные для себя последствия совершения преступления (быть осужденным от имени государства и понести заслуженное наказание), дать в установленном порядке отчет в совершенном им преступлении [10, с. $39 ; 6$, с. $39 ; 14$, с. 10]. Реализация уголовной ответственности заканчивается погашением или снятием судимости [18, с. $71 ; 13$, с. 192-193].

К карательным мерам уголовно-правового воздействия, направленным на реализацию уголовной ответственности, относятся следующие меры:

- наказание (главы 9-10, ст. 88) - мера государственного принуждения, назначаемая по приговору суда;

- смягчение наказания (ч. 2 ст. 10 , ч. 6 ст. 15, ст. $61,62,64)$ - по обстоятельствам, смягчающим наказание;

- ужесточение наказания (ст. 63 - обстоятельства, отягчающие наказание); рецидив преступлений (ч. 5 ст. 18) влечет более строгое наказание;

- изменение вида исправительного учреждения (ч. 4 ст. 58);

- $\quad$ замена наказания (ч. 5 ст. 46, ч. 3 ст. 49, ч. 4 ст. 50 , ч. 5 ст. 53 , чч. 2 и 6 ст. 53.1, ч. 3 ст. 59 , ч. 2 ст. 72 , ст. 80 , ч. 3 ст. 81 , амнистия (ч. 2 ст. 84 ) и помилование (ч. 2 ст. 85) в части заменены назначенного наказания более мягким видом наказания);

- сокращение срока (отсрочка отбывания наказания - ч. 4 ст. 82; амнистия и помилование в части сокращения назначенного наказания (ч. 2 ст. 84 и ч. 2 ст. 85 - соответственно);

- $\quad$ судимость (ст. 86, 95), как совокупность ограничений прав и свобод, налагаемых в равном объеме на всех осужденных.

Отдельно можно выделить меры обеспечения реализации уголовной ответственности, которые заключаются в следующем: 
- квалификация преступлений как совокупность приемов и способов применения уголовного закона, предусмотренных самим законом; уголовно-правовая оценка выявленных общественно-опасных деяний с целью решения вопроса о наличии основания и пределов уголовной ответственности [12, с. 51], (общие правила квалификации преступлений - ст. 3, $9,10,11,12$; частные правила квалификации преступлений: 1) в рамках одного состава с особенностями: а) субъективных признаков преступления - ст. 5, 20-28; б) частично неоконченной преступной деятельностью (ст. 29, $30)$; в) соучастия (ст. 32-36); 2) множественности преступлений (ст. 17);

- выдача иностранных граждан и лиц без гражданства, совершивших преступление вне пределов Российской Федерации и находящихся на территории Российской Федерации, иностранному государству для привлечения к уголовной ответственности или отбывания наказания в соответствии с международным договором Российской Федерации (ст. 13).

Помимо карательных уголовных правоограничений (наказание) уголовный закон содержит некарательные уголовно-правовые меры, которые по справедливому мнению А.А. Нечепуренко следует объединить единым понятием - «испытание» $[15$, с. 3], где «испытание есть мера уголовной ответственности, заключающаяся в обязанностях в виде запретов и предписаний, возлагаемых на осужденного под угрозой отбывания наказания в случае уклонения от их исполнения» $[15$, с. 11$]$.

По содержанию эти правоограничения состоят из возлагаемых на испытуемого запретов и предписаний, выполнение которых позволяет убедиться в его способности в дальнейшем вести правопослушный образ жизни. К испытательным (условным) мерам уголовно-правового воздействия следует отнести:

- освобождение от наказания (ст. 79 и 93 - условно-досрочное освобождение от отбывания наказания; ст. 82 - отсрочка отбывания наказания; ст. 82.1 - отсрочка отбывания наказания больным наркоманией);

- условное осуждение (ст. 73, 74);

- принудительные меры воспитательного воздействия (ст. 90, 91).

Что касается последнего вида мер уголовноправового воздействия, то применяются они к несовершеннолетнему и включают следующие за- преты и предписания, позволяющие отнести их к испытательным мерам:

а) предупреждение;

б) передача под надзор родителей или лиц, их заменяющих, либо специализированного государственного органа;

в) возложение обязанности загладить причиненный вред;

г) ограничение досуга и установление особых требований к поведению несовершеннолетнего.

В случае систематического неисполнения несовершеннолетним принудительной меры воспитательного воздействия (испытания) эта мера по представлению специализированного государственного органа отменяется и материалы направляются для привлечения несовершеннолетнего к уголовной ответственности, то есть применения к нему карательных мер уголовно-правового воздействия.

Учитывая, что наказание применяется в целях исправления осужденного, а испытательный срок, назначается для того, чтобы осужденный своим поведением доказал свое исправление, карательные (наказание) и испытательные меры можно объединить в одну группу как совокупность мер уголовно-исправительного воздействия.

Таким образом, основанная на нормах уголовного права обязанность лица, совершившего преступление, претерпевать неблагоприятные для себя последствия совершения преступления выражается не только в отбывании заслуженного наказания, но и в испытательном сроке.

При наличии определенных условий уголовная ответственность не может быть реализована с использованием карательного или исправительного воздействия. Это связано с объективными обстоятельствами, либо субъективными особенностями лица, совершившего общественно-опасное деяние, не связанными с самим фактом совершения конкретного преступления, и носящими не реабилитирующий характер:

- малозначительность (ч. 2 ст. 14) - признание того, что деяние не представляет общественной опасности, т.е. оно не причинило и не создавало угрозу причинения значительного вреда объекту уголовно-правовой охраны [25, с. 71];

- с сроки давности (ст. 78, 83, 94). Под давностью по уголовным делам подразумевается истечение указанных в законе сроков после совершения преступления или же вступления в силу приговора суда, в силу чего привлечение к ответственности или исполнение приговора не 
может иметь места и делает излишним и нецелесообразным само наказание;

- освобождение от наказания: в связи с изменением обстановки (ст. 80.1); в связи с болезнью (ст. 81); освобождение от наказания несовершеннолетних (ст. 92);

- амнистия (ст. 84) в отношении индивидуально не определенного круга лиц в части освобождения от уголовной ответственности либо освобождения от наказания;

- помилование (ст. 85) в отношении индивидуально определенного лица, в части освобождения лица, осужденного за преступление, от дальнейшего отбывания наказания;

- освобождение от уголовной ответственности вследствие стечения тяжелых обстоятельств: если дезертирство явилось следствием стечения тяжелых обстоятельств (ст. 338); если вовлечение несовершеннолетнего в занятие бродяжничеством совершено родителем вследствие стечения тяжелых жизненных обстоятельств, вызванных утратой источника средств существования или отсутствием места жительства (ст. 151 УК РФ).

Данные меры уголовно-правового воздействия можно определить как уголовно-правовые меры безусловной единичной не реабилитирующей декриминализации. Так, изменение обстановки или истечение сроков давности не связано с выполнением каких-либо запретов или предписаний, а является объективным признанием самоисправления лица с учетом конкретных обстоятельств.

Итак, проведенный анализ мер уголовно-правового воздействия позволил сделать вывод, что такие меры нельзя отождествлять исключительно с мерами уголовной ответственности, мерами принуждения и помимо мер принуждения (реализации уголовной ответственности - наказания и судимости) уголовный закон содержит меры:

- уголовно-предупредительного воздействия (добровольный отказ и др.);

- уголовно-профилактического воздействия (адаптация, предупреждение и др.);
- уголовно-восстановительного воздействия (возмещение вреда, деятельное раскаяние и др.);

- уголовно-исправительного воздействия (в части испытаний);

- обеспечения реализации уголовной ответственности (квалификация, выдача);

- единичной не реабилитирующей декриминализации (амнистия и др.);

- уголовно-лечебного воздействия (принудительные меры медицинского характера).

Анализ уголовного законодательства, регламентирующего механизм уголовно-правового воздействия на участников общественных отношений, возникающих в результате совершения преступления, позволил сформулировать определение «меры уголовно-правового воздействия», под которыми предлагается понимать различные виды, закрепленных в уголовном законе, форм и средств специальной деятельности государства, общества и отдельных граждан, применяемые для достижения как общих целей уголовно-правового противодействия преступности (профилактика, борьба с преступлениями, минимизация и (или) ликвидация последствий их совершения), так и самостоятельных целей для каждой группы мер воздействия, отличающихся присущим только им результатом реализации:

- уголовно-правовые меры предупреждения (профилактики) преступлений;

- уголовно-правовых меры пресечения преступлений;

- меры реализации уголовной ответственности;

- по характеру воздействия это меры:

- уголовно-предупредительного воздействия;

- уголовно-профилактического воздействия;

- уголовно-восстановительного воздействия;

- уголовно-исправительного воздействия (карательные (наказание) и испытательные меры);

- обеспечения реализации уголовной ответственности

- единичной не реабилитирующей декриминализации;

- уголовно-лечебного воздействия.

\section{Библиография:}

1. «О деятельности органов внутренних дел по предупреждению преступлений». Утв. Приказом МВД России от 17 января 2006 г. № 19 (в ред. Приказов МВД РФ от 29.01.2009 N 60, от 21.08.2010 N 618, от 25.12.2010 N 883) // Доступ из справочно-правовой системы Консультант плюс. URL : http://base.consultant.ru/cons/cgi/online. cgi?req=doc;base=LAW;n=129872 (дата обращения: 08.06.2015г.).

2. «0 дополнительных мерах по укреплению правопорядка в Российской Федерации». Утв. Указом Президента РФ от 18 августа 1993 г. № 1390 // Собрание актов Президента и Правительства РФ". 1993. № 38. Ст. 3517.

3. «0 мерах по усилению контроля органами внутренних дел за частной детективной и охранной деятельностью». Приказ МВД России от 31 декабря 1999 г. № 1105 (ред. от 30.08.2011) // Доступ из справочно-правовой системы 
Консультант плюс. URL : http://base.consultant.ru/cons/cgi/online.cgi?req=doc;base=LAW;n=131328 (дата обращения: 08.06.2015 г.).

4. «0 судебной практике применения законодательства, регламентирующего особенности уголовной ответственности и наказания несовершеннолетних». Постановление № 1 Пленума Верховного суда Российской Федерации от 1 февраля 2011 г. // БВС РФ. 2011. № 4.

5. Об утверждении государственной программы Российской Федерации «Обеспечение общественного порядка и противодействие преступности». Утв. Постановлением Правительства РФ от 15 апреля 2014г. № 345//С3 2014. № 18 (часть IV). Ст. 2188.

6. Загородников Н.И. О пределах уголовной ответственности // Сов. гос. и право. 1967 № 7 С.39.

7. Бавсун М.В. Уголовно-правовое воздействие : идеология, цели и средства реализации. Автореф. дисс. ... докт. юрид. наук. - Омск: Омская академия Министерства внутренних дел Российской Федерации, 2013. С. 13.

8. Гришанин П.Ф. Меры уголовно-правового воздействия на преступность и их реализации органами внутренних дел. М.: Академия МВД России, 1996. С. 3

9. Звечаровский И.Э. Понятие мер уголовно-правового характера // Законность. 2007. № 1. С. 20.

10. К Карпушин М.П., Курляндский В.И. Уголовная ответственность и солстав преступления. М. 1974. С. 39.

11. Концепция уголовно-правовой политики РФ // Официальный сайт Общественной палаты PФ. URL : http://www. oprf.ru/discussions/1389/newsitem/17889 (дата обращения: 19.03.2015).

12. Кудрявцев В.Н. Общая теория квалификации преступлений. М., 1974. С. 51.

13. Курс уголовного права. Общая часть. В 2 т.-М.: МГУ. 1999. С. 192-193.

14. Наташев А.Е., Стручков Н.А. Основы теории исправительно-трудового права.-М.: Юрид. лит. 1967. С. 10.

15. Нечепуренко А.А. Испытание в уголовном праве Российской Федерации: Автореф. дисс. ... докт. юрид. наук. Омск: Омская академия МВД России, 2009. С. 3.

16. Ображиев К.В. Уголовно-правовые нормы с двойной превенцией // Проблемы укрепления законности и правопорядка: наука, практика, тенденции. 2010. № 3. С. 170-171.

17. Трунцевский Ю.В. Российское уголовно-превентивное право: признаки отрасли // Российский криминологический взгляд. 2010. № 3. С.169.

18. Уголовное право РФ. Общая часть / Под ред. Б.В. Здравомыслова. - М.: Юристъ. 1996. С 71.

19. Уголовно-правовое воздействие. Монография / под ред. А.И. Рарога. М.: Проспект, 2012. // Доступ из справочноправовой системы Консультант плюс.

20. Уголовный кодекс РСФСР // Ведомости ВС РСФСР. 1960. № 40. Ст. 591.

21. Федеральный закон от 06.03.2006 N 35-ФЗ (ред. от 31.12.2014) "О противодействии терроризму" // СЗ РФ. 2006. № 11. Ст. 1146.

22. Федеральный закон от 25.07.2002 N 114-Ф3 (ред. от 31.12.2014) "О противодействии экстремистской деятельности" // СЗ РФ. 2002. № 30. Ст. 3031.

23. Федеральный закон от 25.12.2008 N 273-ФЗ (ред. от 22.12.2014) "О противодействии коррупции" // СЗ РФ. 2008. № 52 (ч. 1). Ст. 6228.

24. Федеральный закон от 3 апреля 1995 № 40-ФЗ (ред. от 22.12.2014) "О Федеральной службе безопасности" // СЗ РФ. 1995. № 15. Ст. 1269.

25. Цепелев В.Ф., Мартыненко Н.Э. Малозначительность деяния в судебной практике и интересы потерпевшего // Уголовное право. 2012. № 3. С. 71-74.

26. Ширяев В.Ф. Наказание в системе мер уголовно-правового воздействия: содержание, проблемы совершенствования: Дис. ... канд. юрид. наук. Ярославль, 2001. С. 49.

27. Костенников М.В., Куракин А.В. К вопросу об основании административной ответственности в российском праве // NB: Административное право и практика администрирования.-2013.-10.-С. 75-88. DOI: 10.7256/23069945.2013.10.10153. URL: http://www.e-notabene.ru/al/article_10153.html

\section{References (transliterated):}

1. «O deyatel'nosti organov vnutrennikh del po preduprezhdeniyu prestuplenii». Utv. Prikazom MVD Rossii ot 17 yanvarya 2006 g. № 19 (v red. Prikazov MVD RF ot 29.01.2009 N 60, ot 21.08.2010 N 618, ot 25.12.2010 N 883) // Dostup iz spravochno-pravovoi sistemy Konsul'tant plyus. URL : http://base.consultant.ru/cons/cgi/online. cgi?req=doc;base=LAW;n=129872 (data obrashcheniya: 08.06.2015g.).

2. «O dopolnitel'nykh merakh po ukrepleniyu pravoporyadka v Rossiiskoi Federatsii». Utv. Ukazom Prezidenta RF ot 18 avgusta 1993 g. № 1390 // Sobranie aktov Prezidenta i Pravitel'stva RF". 1993. № 38. St. 3517.

3. «O merakh po usileniyu kontrolya organami vnutrennikh del za chastnoi detektivnoi i okhrannoi deyatel'nost'yu». Prikaz MVD Rossii ot 31 dekabrya 1999 g. № 1105 (red. ot 30.08.2011) // Dostup iz spravochno-pravovoi sistemy Konsul'tant plyus. URL : http://base.consultant.ru/cons/cgi/online.cgi?req=doc;base=LAW;n=131328 (data obrashcheniya: 08.06.2015 g.).

4. «0 sudebnoi praktike primeneniya zakonodatel'stva, reglamentiruyushchego osobennosti ugolovnoi otvetstvennosti i nakazaniya nesovershennoletnikh». Postanovlenie № 1 Plenuma Verkhovnogo suda Rossiiskoi Federatsii ot 1 fevralya 2011 g. // BVS RF. 2011. № 4. 
Административное и муниципальное право 6 (90) • 2015

5. Ob utverzhdenii gosudarstvennoi programmy Rossiiskoi Federatsii «Obespechenie obshchestvennogo poryadka i protivodeistvie prestupnosti». Utv. Postanovleniem Pravitel'stva RF ot 15 aprelya 2014g. № 345//SZ 2014. № 18 (chast' IV). St. 2188.

6. Zagorodnikov N.I. O predelakh ugolovnoi otvetstvennosti // Sov. gos. i pravo. 1967 № 7 S.39.

7. Bavsun M.V. Ugolovno-pravovoe vozdeistvie : ideologiya, tseli i sredstva realizatsii. Avtoref. diss. ... dokt. yurid. nauk. Omsk: Omskaya akademiya Ministerstva vnutrennikh del Rossiiskoi Federatsii, 2013. S. 13.

8. Grishanin P.F. Mery ugolovno-pravovogo vozdeistviya na prestupnost' i ikh realizatsii organami vnutrennikh del. M.: Akademiya MVD Rossii, 1996. S. 3

9. Zvecharovskii I.E. Ponyatie mer ugolovno-pravovogo kharaktera // Zakonnost'. 2007. № 1. S. 20.

10. Karpushin M.P., Kurlyandskii V.I. Ugolovnaya otvetstvennost' i so stav prestupleniya. M. 1974. S. 39.

11. Kontseptsiya ugolovno-pravovoi politiki RF // Ofitsial'nyi sait Obshchestvennoi palaty RF. URL : http://www.oprf.ru/ discussions/1389/newsitem/17889 (data obrashcheniya: 19.03.2015).

12. Kudryavtsev V.N. Obshchaya teoriya kvalifikatsii prestuplenii. M., 1974. S. 51.

13. Kurs ugolovnogo prava. Obshchaya chast'. V 2 t.-M.: MGU. 1999. S. 192-193.

14. Natashev A.E., Struchkov N.A. Osnovy teorii ispravitel'no-trudovogo prava.-M.: Yurid. lit. 1967. S. 10.

15. Nechepurenko A.A. Ispytanie v ugolovnom prave Rossiiskoi Federatsii: Avtoref. diss. ... dokt. yurid. nauk. - Omsk: Omskaya akademiya MVD Rossii, 2009. S. 3.

16. Obrazhiev K.V. Ugolovno-pravovye normy s dvoinoi preventsiei // Problemy ukrepleniya zakonnosti i pravoporyadka: nauka, praktika, tendentsii. 2010. № 3. S. 170-171.

17. Truntsevskii Yu.V. Rossiiskoe ugolovno-preventivnoe pravo: priznaki otrasli // Rossiiskii kriminologicheskii vzglyad. 2010. № 3. S.169.

18. Ugolovnoe pravo RF. Obshchaya chast' / Pod red. B.V. Zdravomyslova. - M.: Yurist"'. 1996. S 71.

19. Ugolovno-pravovoe vozdeistvie. Monografiya / pod red. A.I. Raroga. M.: Prospekt, 2012. // Dostup iz spravochno-pravovoi sistemy Konsul'tant plyus.

20. Ugolovnyi kodeks RSFSR // Vedomosti VS RSFSR. 1960. № 40. St. 591.

21. Federal'nyi zakon ot 06.03.2006 N 35-FZ (red. ot 31.12.2014) "O protivodeistvii terrorizmu" // SZ RF. 2006. № 11. St. 1146.

22. Federal'nyi zakon ot 25.07.2002 N 114-FZ (red. ot 31.12.2014) "O protivodeistvii ekstremistskoi deyatel'nosti" // SZ RF. 2002. № 30. St. 3031.

23. Federal'nyi zakon ot 25.12.2008 N 273-FZ (red. ot 22.12.2014) "O protivodeistvii korruptsii" // SZ RF. 2008 . № 52 (ch. 1). St. 6228.

24. Federal'nyi zakon ot 3 aprelya 1995 № 40-FZ (red. ot 22.12.2014) "O Federal'noi sluzhbe bezopasnosti" // SZ RF. 1995. № 15. St. 1269.

25. Tsepelev V.F., Martynenko N.E. Maloznachitel'nost' deyaniya v sudebnoi praktike i interesy poterpevshego // Ugolovnoe pravo. 2012. № 3. S. 71-74.

26. Shiryaev V.F. Nakazanie v sisteme mer ugolovno-pravovogo vozdeistviya: soderzhanie, problemy sovershenstvovaniya: Dis. ... kand. yurid. nauk. Yaroslavl', 2001. S. 49.

27. Kostennikov M.V., Kurakin A.V. K voprosu ob osnovanii administrativnoi otvetstvennosti v rossiiskom prave // NB: Administrativnoe pravo i praktika administrirovaniya.-2013.-10.-C. 75-88. DOI: 10.7256/2306-9945.2013.10.10153. URL: http://www.e-notabene.ru/al/article_10153.html 